\title{
P. Krugman's Core-Periphery Model. Case Study: The Tourist Demand on the Romanian Seaside
}

\author{
Ruxandra-Luminița GHEORGHE \\ University of Bucharest, Faculty of Geography \\ ruxandra.gheorghe1@s.unibuc.ro
}

\begin{abstract}
Krugman's model is a new approach for Romania, even more applied to the Black Sea seaside. The tourist demand in such a way reveals the relations not only economic, but also of another nature between the core and the periphery. The data clearly show that this model is a forceful one, applicable not only to the Romanian seaside, but also to the region, country or continent, and its study can reveal very interesting conclusions: the influence of the core on the periphery, how the North and the South interact in the chosen model and how seasonality affects seaside tourism.
\end{abstract}

Keywords: Krugman, core-periphery, tourist demand, seaside, seasonality

\section{INTRODUCTION}

The tourist market, as a place of confrontation of supply and demand and as the main source of information, is a reference element of the tourist activity, sensitive to any fluctuation at micro and macro-economic level.

The analysis of the indicators resulting from the analysis of the complexity of the service providers and of the typology of consumers at public and private level can show the development or regression of the tourist market, respectively the efficiency of the growth efforts and consumer satisfaction.

The development of tourism must be carried out in such a way as to contribute to the improvement of the quality of life in a responsible manner on the part of all those involved in the tourism industry, both in the public and private sectors. They must combine the inherent disadvantages with the advantages, some of them unique in the world or, from another perspective, the maximum satisfaction obtained by the tourist by buying goods and services at the desired price.

The research of the tourism industry is not new, many authors having tried to develop, in a useful manner, a model of it. In order to have an objective study, the interaction of several study areas is required, more specifically a PESTEL research over approximately 55 years (1965-2018). However, this article will show a new facet of the Romanian tourism industry in terms of tourism demand, approached in a new way based on a method developed by Paul Krugman (1991).

To this model is added the seasonality of Romanian tourism, considering that it operates only 3 months in the summer season, respectively 2 months in the off-season, which requires a special research of this feature.

The study is limited to research on the Romanian seaside and tourism in this segment, showing some of the current problems, being important both for public administration and for those in the private industry. Krugman's model is not infallible, but it is observable throughout the research period, and seasonality as a specific feature of coastal tourism, is likely to bring additional data that can lead to a better understanding of the problem studied.

The data used comes from two sources:

- public ones, such as those of the National Institute of Statistics and the Ministry of Tourism;

- private ones, collected from the territory along the maritime coast in season and off-season in 2017, respectively from the internet, and based on a survey focusing on consumer theory. The survey consists of two parts: the situation in 2017 and a comparison with the period 1965-1989. 


\section{KRUGMAN'S CORE-PERIPHERY MODEL}

In the current economic context, the core-periphery effect is more visible than ever, therefore it is necessary to analyze its effects on Romanian tourism, especially in order to counteract the too strong development of rich centers and to help the periphery benefit from the same advantages as the center.

The monopolistic concentration of the center leads to economic impositions to the detriment of the peripheral regions and, through this, the partial development of the latter. Fujita, Krugman and Venebles (2001) show that, at a certain historical moment, this effect has the role of unbalancing economies, respectively, depending on the evolution of GDP, of strengthening the economy.

This model shows that geography and trade are likely to influence the growth and decline of a region, as Krugman showed in his fundamental paper: to develop a simple model that shows how a country can endogenously become differentiated into an industrialized "core" and an agricultural "periphery".

The core-periphery model consists in the development of a strong center, with clear advantages over the periphery, which is impoverished in terms of industry, services and population.

While the center is enriched by various investments that attract more money, but also salary increases, higher rents, more staff, in the periphery there is an acute lack of investment, low wages, low rents that often do not cover the ordinary expenses of a household.

One of the most important economic indicators, mentioned by Krugman himself, is the migration of the population from the periphery to the center. Throughout history, this phenomenon can be observed, obviously not only in a single region or a country, but also at the continental level.

In our representation below, we distinguish this Krugman model on the Romanian coast: Constanța Municipality as the main nucleus for the northern part of the coast and Mangalia as the secondary nucleus for the southern part of the coast.

A special component of the market, respectively of the tourist services, is represented by the set of sale-purchase documents whose legal object is represented by the tourist products from a certain space and certain economic relations, forming the tourist market. The two main components - demand and supply - complement each other, being dependent on each other: demand is the result of supply, and supply is a cumulation and a synthesis of information provided by tourists (Charles and Ritchie, 2011).

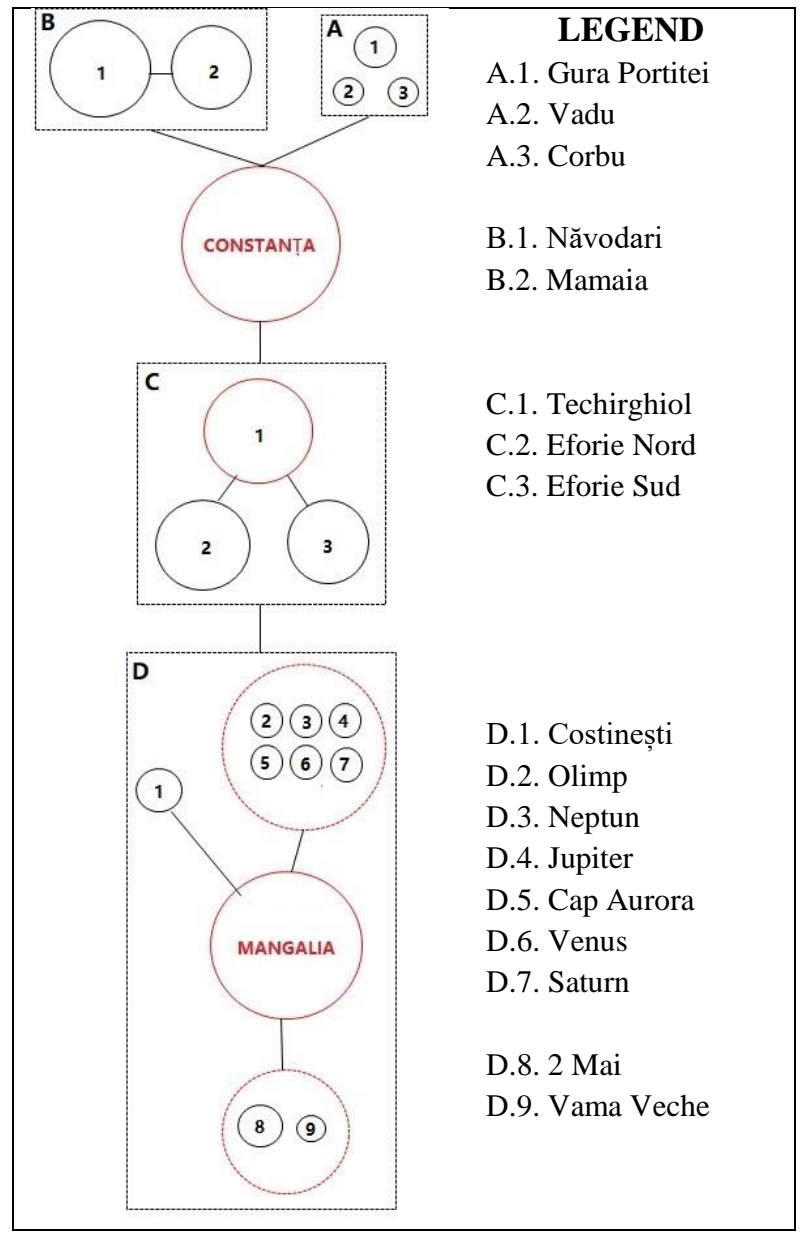

Figure 1 The Krugman model applied to the Romanian coast. Source: Author

Naturally, in relation to supply, the decision of tourist consumption occurs, the connection is made only at the beginning of consumption and the place of supply is always the same as that of consumption: tourist demand therefore consists in all requirements manifested or not yet manifested for the approximation of tourist products, with tourist consumption being its result (Goeldner and Ritchie, 2011).

The peculiarities of the tourist demand are:

- it is elastic, being permanently subject to the fluctuation of economic, social, demographic, psychological factors, etc.;

- high degree of heterogeneity and complexity, the study requiring the segmentation of the sample according to different criteria (age, occupation, consumption habits, etc.); 
- high degree of mobility, mainly caused by supply rigidity;

- strong seasonal character, the reason being the dependence of the tourist circulation on certain factors, respectively on the unequal distribution and on the non-storable character of the tourist offer (Lickorish and Jenkins, 2000).

The modeling of the Romanian seaside according to Krugman's model incites empirical speculation; however, together with the official statistical data provided by the National Institute of Statistics and the Ministry of Tourism (official data that, incidentally, do not correspond to each other!) we can make a somewhat accurate estimate of situation.

\section{THE MAIN TOURISM DEMAND CHARACTERISTICS ON THE ROMANIAN SEASIDE}

In the southeastern part of Romania, the most visited destination is Constanta County, the localities along the Black Sea seaside being the most attractive for tourists. Excluding the spa resort Techirghiol from the Peripheral Area no. 3 in the North, $97.60 \%$ of tourists choose these localities, spending the night there in a similar percentage: $96.70 \%$.

\subsection{Northern Core-Periphery Area}

In the analysis of the present situation we will take into account that in the Peripheral Area no. 1 from the North (which contains the localities from the wild area Corbu and Vadu and the semi-wild Gura Portitei), although having a few registered accommodation structures, most tourists spend the night in tents, motorhomes, personal cars, residents' houses (located about $5 \mathrm{~km}$ from the beach) or directly on the beach, therefore we will not know the actual number of arrivals in this region.

\section{a) Tourist Arrivals}

From an administrative-territorial point of view, Gura Portitei resort is located in Tulcea County. In terms of the statistical data, it can be seen that in 2009 was a crash for the Romanian economy: while 3,213 tourists were officially reported in 2007 , in
2008 - 9,824 tourists, in 2009 the number decreased to 2,566 tourists. It was only in 2013 that the tourist arrivals approached the value of those from 2008 (9,457 tourists); subsequently, through spectacular increases and decreases, in 2018 only 8,010 tourists were registered.

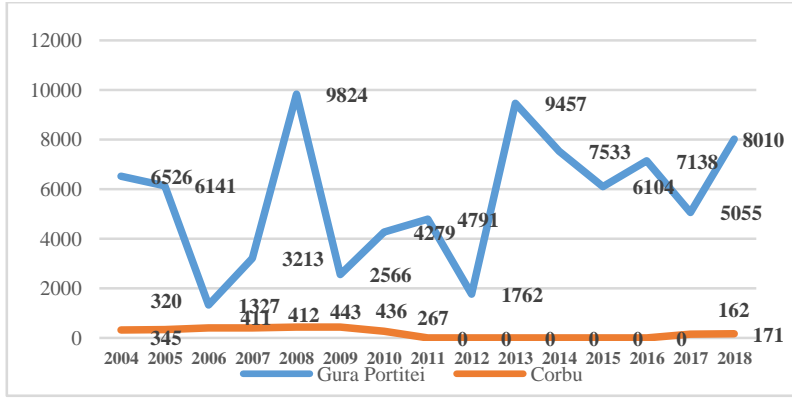

Figure 2 Tourist Arrivals in the Northern Peripheral Wilderness Area Between 2004-2018. Source: N.S.I.

Also, from the official statistical data, in Corbu locality there were, in 2008, 412 tourists. Subsequently, in the period 2011-2016 no tourist is registered, in 2017 only 162 and 171 in 2018. We do not have any statistical data about Vadu. As we mentioned, in reality the tourists who come to these areas are much more numerous.

Statistical data are available on tourist arrivals for the other localities in the Northern CorePeriphery Area, grouped as follows: Navodari City with Navodari Resort (Mamaia Nord), Mamaia Resort with the center of Constanta and Eforie Nord with Eforie Sud.

The city of Navodari, together with Navodari Resort (Mamaia Nord) had in 2018 70,518 arrivals. A significant increase of approximately six times higher than in 2008 (12,347 arrivals) was registered in Nord Periphery no. 2, with approximately half in 2013: 33,289 arrivals.

Five years after the global economic crisis, Constanta and the Pearl of the Romanian seaside Mamaia, recovered bringing a record of 575,698 tourists; in 2008 there were only 461,086 tourists, with a slight decrease in 2013 - 436,546 arrivals.

Peripheral area no. 3 in the North also attracts a significant number of tourists. The two Eforie resorts have a slight growth trend of $1.50 \%$ in 10 years (2008 - 145,222 arrivals, 2018 - 218,813 arrivals), although in 2013 it had a decrease of $20 \%$ (117,380 arrivals). Techirghiol has a steady increase 
of $1.80 \%$, from 8,636 arrivals in 2008 to 15,611 arrivals in 2018.

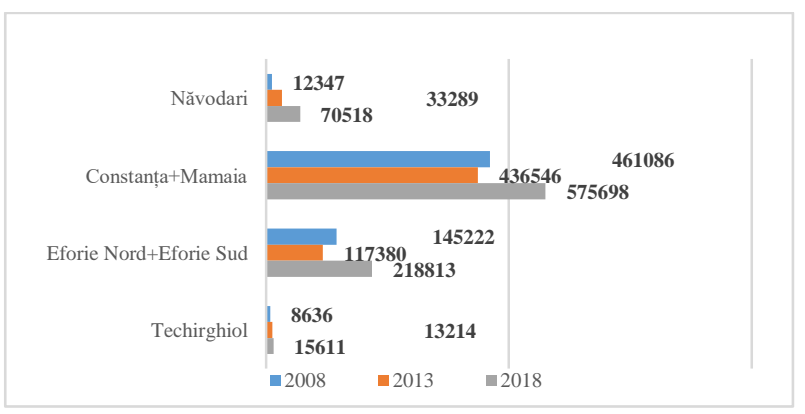

Figure 3 Tourist Arrivals in the Northern

Core-Periphery Area Between 2008-2018. Source: N.S.I.

The tourist arrivals in Constanta County, depending on the seasonality, show the following:

- in 2018, 89\% of the total number of tourists were registered in May-September, and in JulyAugust there was a maximum of consumers (approximately $2 / 3$ of them): $62.30 \%$;

- the share remained relatively constant between 2013-2018, thus in $201488.60 \%$ of tourists were reported in the season, of which $64.20 \%$ during the peak;

- foreign tourists increased $17.30 \%$ in the offseason, being more numerous $(27.50 \%)$ than the Romanian ones (10.20\%);

- the number of foreign tourists remained small (below 5\%), the growth rate being half that of Romanian tourists.

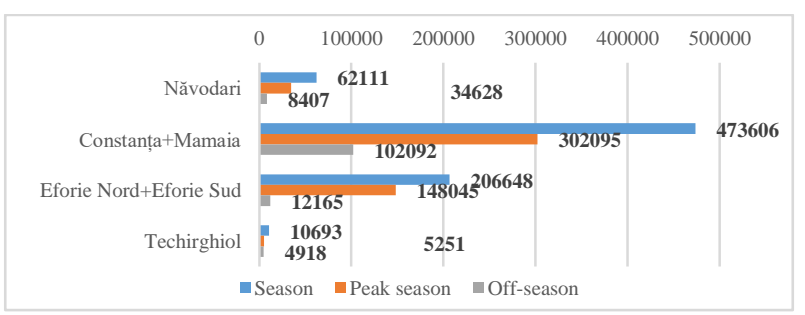

Figure 4 Seasonality of Tourist Demand in the Core-Periphery Area in the North (Tourist Arrivals). Source: N.S.I.

In the North Area, the seasonality of tourist arrivals is as follows:

- in Navodari, out of a maximum number of 62,111 arrivals, $55.75 \%$ of them were made during the peak season: 34,628 registered arrivals. In the off-season, there were less than $15 \% \quad(8,407$ arrivals);
- in Constanta and Mamaia, the area with the highest records regarding the number of tourists arriving on the seaside, $63.80 \%(302,095)$ of the reported arrivals were in the peak season (out of a total of 473,606 arrivals); in the off-season, there were just over 100,000 arrivals;

- Eforie Nord and Eforie Sud were the busiest in the peak season $(71.60 \%$ of tourists, 148,045 registered arrivals), here a total of 206,648 tourist arrivals were reported. In the off-season, there was an extremely small number of 12,165 tourists;

- Techirghiol is almost constant during the year, both in season and in the off-season, due to the spa treatments that are also performed in winter. Thus, while in the off-season there were 4,918 arrivals, only 5,251 arrivals are reported in maximum peak out of a total of 10,693 registered arrivals.

\section{b) Tourist Overnight Stays}

Regarding the number of overnight stays, the first place is held by the Municipality of Constanta (35.30\%), followed by Eforie (18.80\%), Navodari $(4.50 \%)$ and Techirghiol (2.6\%), all the others having a share of less than $1 \%$.

The most dynamic resort was Navodari (Mamaia Nord) which recorded an increase of $607.80 \%$ (from 37,453 to 227,636 overnight stays), followed by $140.20 \%$ in Techirghiol (increase from 94,498 to 132,496 overnight stays), $131.10 \%$ in Eforie Nord and Eforie Sud (from 718,635 to 942,290 overnight stays, with a decrease of $59.60 \%$ - 450,268 overnight stays in 2013) and $105.20 \%$ in Mamaia (from $1,679,252$ to $1,767,115$ overnight stays, with a decrease of $18.50 \%-1,406,403$ overnight stays in 2013).

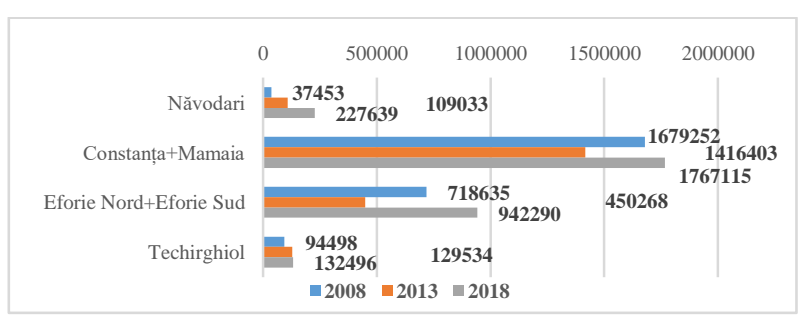

Figure 5 Tourist Overnight Stays in The Northern Core-

Periphery Area Between 2008-2018. Source: N.S.I.

Regarding the number of overnight stays, the discrepancies are very large, as follows:

- in 2018: $67.60 \%$ of the overnight stays at the peak of the season, out of a total of $92.20 \%$ in the whole Constanta county; 
- in the off-season only $25.30 \%$ of the overnight stays of foreign tourists are reported and only $7.30 \%$ of the overnight stays of Romanian ones;

- the share of overnight stays of tourists barely reaches $3.80 \%$ and decreases continuously (during 2014-2018 it decreased by $18.50 \%$ ), the reason being the decrease of the average length of stay from 4.6 to 3.1 tourist-days;

- in the summer season there is a high concentration of tourists in the tourist localities on the seaside;

- Eforie Nord and Eforie Sud comprise $94.40 \%$ of the number of tourists and $96.30 \%$ of the number of overnight stays take place during the season.

- the pressure exerted by the peak season is slightly lower, only $67.70 \%$ tourists and $70.20 \%$ overnight stays being recorded;

- in Techirghiol, a spa locality, less dependent on the changes of the seasons, the seasonality is not much affected, $31.50 \%$ tourists and $38.80 \%$ overnight stays being recorded.

In Navodari, out of a total of 215,482 overnight stays throughout the season, 138,683 take place during the peak period and only 12,157 overnight stays were recorded in the off-season.

Constanta and Mamaia have the most overnight stays on the entire seaside, respectively 1,554,762 overnight stays, of which $1,060,728$ take place in the peak season; tourists that come in the off-season have only 212,353 nights.

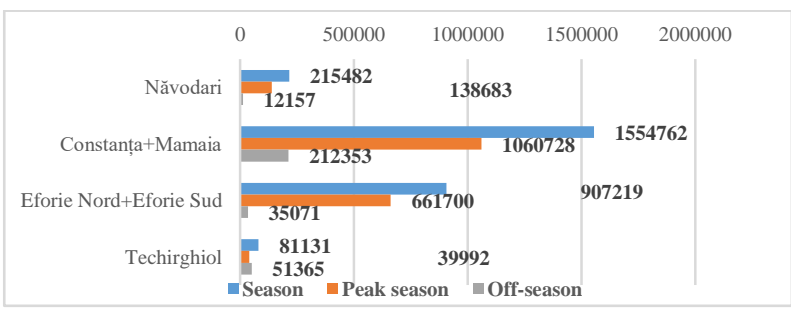

Figure 6 Seasonality of Tourist Demand in the Northern

Core - Periphery Area (Tourist Overnight).

Source: N.S.I.

Eforie Nord and Eforie Sud have just over 900,000 overnight stays, of which 661,600 are in season, to which are added 35,071 off-season overnight stays.

Techirghiol has a special configuration, the number of arrivals in the off-season is almost two thirds higher than that of arrivals in the peak season
(51,365 to 39,992 overnight stays), with a total of 81,131 overnight stays.

\section{c) Length of Stay}

With the exception of the city of Navodari which had an increase of $6.60 \%$ (from 3 tourist-days to 3.2 tourist-days, with a maximum in 2013 of 3.3 touristdays), all other tourist destinations registered constant decreases: $-16.12 \%$ in Mamaia (from 3.6 to 3.1 tourist-days), $-13.95 \%$ in Eforie Nord and Eforie Sud (from 4.9 to 4.3 tourist-days) and $28.23 \%$ in Techirghiol (from 10.9 to 8.5 tourist-days). Noteworthy is the big difference between the average lengths of stay recorded in Techirghiol and the other localities because it is a spa resort destination, and the treatments require time to have the expected effect.

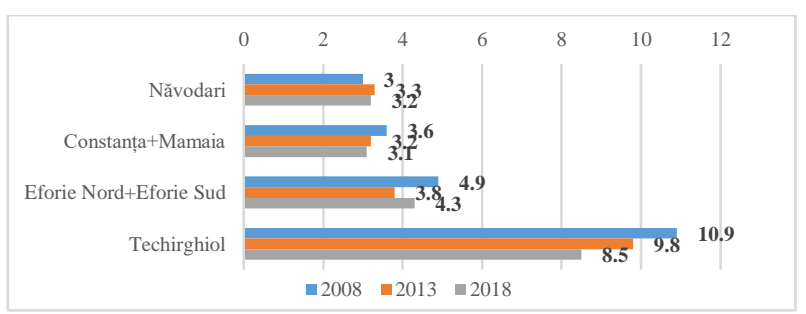

Figure 7 Length Of Stay (Number Of Days) In The Northern Core-Periphery Area Between 2008-2018. Source: N.S.I.

\subsection{Southern Core-Periphery Area}

As in the Northern Core-Periphery Area, statistical data on tourist arrivals from some resorts were calculated together with other resorts. Thus, the following groups are formed:

- The Mangalia core was grouped with the resorts located in the Peripheral Area no. 2 from the South, i.e. those from the Comorova Forest Area: Neptun- Olimp Jupiter, Cap Aurora, Venus, Saturn;

- Peripheral Area no. 3 from the South was calculated together, being a relatively small number: 2 Mai and Vama Veche;

Here too, as in the Peripheral Area no. 1 in the North, the wild and semi-wild resorts were occupied by tourists, who stayed with the locals, in tents (outside the campsites) or in their own cars and they were not reported anywhere. However, consumption in food service structures shows, at least in the statistical data, a large presence, which is actually observed on the beach. 


\section{a) Tourist Arrivals}

The most spectacular increase was in the 2 MaiVama Veche group, of $465.30 \%$ (from 3,720 to 17,323 arrivals), followed by Costinesti with $232.40 \%$ (from 23,926 to 55,608 arrivals) and Mangalia with the Comorova Forest Area with approximately $111.90 \%$ (from 303,762 to 339,824 arrivals).

It can be noticed that the Southern Area does not cover even by far the number of arrivals from the Northern Area (Constanta with Mamaia), with differences of more than twice as big:

- In 2008 there were 331,411 arrivals in the South Area compared to 627,291 arrivals in the North Area (representing - 47.17\%);

- in 2013 a difference of $58.86 \%$ is reported between the two Areas $(247,016$ compared to 600,429 arrivals);

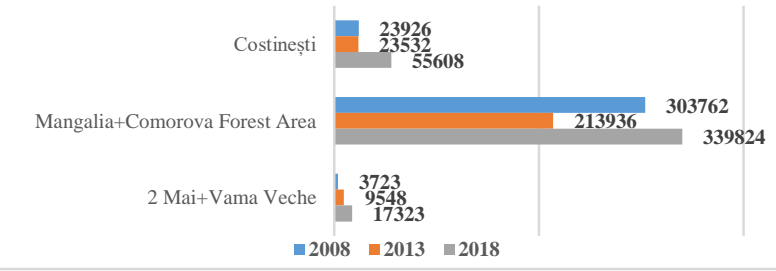

Figure 8 Tourist Arrivals in the Southern Core-Periphery Area Between 2008-2018. Source: N.S.I.

- in 2018 the difference is slightly smaller than in 2013 (by 5.73\%), the number of those arriving being 880,640 in the North Area and 412,755 in the South Area (-53.13\%).

The South Center, represented by Mangalia and the six resorts in the Peripheral Area no. 2 from the South, mentioned above, did not exceed the number of tourists who arrived in 2008 in the North Center, represented by the Municipality of Constanta and Mamaia Resort $(461,086)$, reaching 303,762. Then, not even 5 years after the global economic crisis, the number of tourist arrivals from the South Core did not reach the one in the North: 213,936 versus 436,546 times in 2018. In the South Core 339,824 tourists arrived compared to 575,698 , arriving in the North.

Regarding the two rural areas in the south, i.e. Periphery no. 1 from the South - Costinesti - and Periphery no. 3 from the South - Limanu Commune (with the resorts 2 Mai and Vama Veche) -, even in the case of taking them into account together the number of tourists (in 2018 there were 72,931) does not reach the one of the two Eforie resorts: 218,813, but slightly exceeds the one from Navodari Resort and Navodari City, from Periphery no. 2 from the North: 70,518 tourists.

In the South, things are a little different:

- in Costinesti, 55,508 tourists arrive, of which 49,588 arrivals are registered in the peak season, which represents $89.30 \%$, being the busiest resort in this period; in the off-season, no tourists step on the sea shore;

- Mangalia and the localities around it from Comorova Forest have the most work during the peak season when 258,989 tourists arrive, considering that 330,756 tourists are registered throughout the season. In the off-season, there are almost 10,000 tourists who benefit from spa treatments;

- in Limanu (2 Mai and Vama Veche) the same strong activity is maintained during the peak season $(12,685$ arrivals), with a total of 17,184 tourists coming there during the season. In the off-season, 139 tourists were registered.

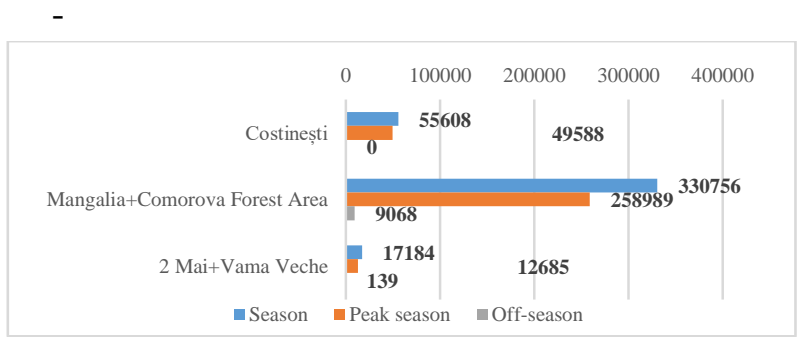

Figure 9 Seasonality of Tourist Demand in the Southern Core-Periphery Area (Tourist Arrivals). Source: N.S.I.

\section{b) Tourist Overnight Stays}

Regarding the number of overnight stays, the first place is held by the Municipality of Mangalia (32.70\%), followed by Costinesti (4.20\%) and Limanu (1.10\%). All other localities in the South, as we have shown, attracted less than $0.80 \%$ of the number of overnight stays recorded.

The most spectacular increase was in the commune of Limanu (Vama Veche and 2 Mai) with about $192.10 \%$, followed by the resorts of Costinesti $(+87.80 \%)$, Ovidiu $(+50.50 \%)$ and Venus (+40, 20\%).

Costinesti resort had an increase of $87.80 \%$ in 2018 compared to 2008 (from 110,812 to 208,096 overnight stays), even if in 2013 it had a decrease to 93,446 overnight stays (-15.68\%). 
Mangalia and Comorova Forest Area recorded a decrease of $5.70 \%$ compared to 2008 (from $1,739,522$ to $1,640,192$ overnight stays), but had an increase of $27.90 \%$ compared to $2013(1,155,230$ overnight stays).

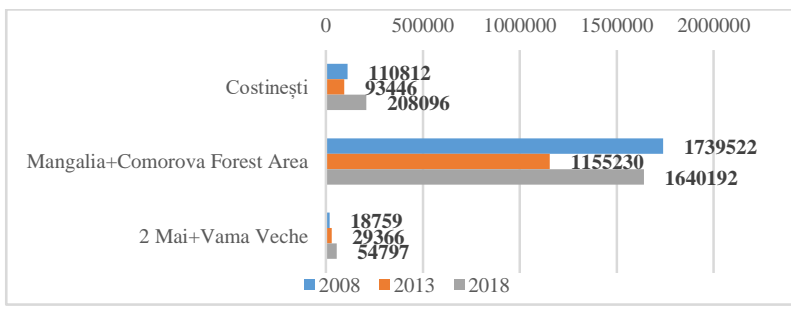

Figure 10 Tourist Overnight Stays in the Southern Core-Periphery Area Between 2008-2018. Source: N.S.I

Regarding the number of overnight stays, the discrepancies are very large, as follows:

- in 2018: $67.60 \%$ of the overnight stays at the peak of the season, out of a total of $92.20 \%$ in the whole Constanta county;

- in the off-season only $25.30 \%$ of the overnight stays of foreign tourists are reported and only $7.30 \%$ of the overnight stays of Romanian ones;

- the share of overnight stays of tourists barely reaches $3.80 \%$ and decreases continuously (during 2014-2018 it decreased by $18.50 \%$ ), the reason being the decrease of the average length of stay from 4.6 to 3.1 tourist days;

- in the summer season there is a high concentration of tourists in the tourist localities on the seaside;

- Eforie Nord and Eforie Sud comprise $94.40 \%$ of the number of tourists and $96.30 \%$ of the number of overnight stays take place during the season.

- the pressure exerted by the peak season is slightly lower, with only $67.70 \%$ tourists and $70.20 \%$ overnight stays being recorded;

- in Techirghiol, a locality with a spa treatment option, less dependent on the changes of the seasons, the seasonality is not much affected, with $31.50 \%$ tourists and $38.80 \%$ overnight stays being recorded.

In Navodari, out of a total of 215,482 overnight stays throughout the season, 138,683 take place during the peak period and only 12,157 overnight stays were recorded in the off-season.

Constanta and Mamaia have the most overnight stays on the entire seaside, respectively $1,554,762$ overnight stays, of which $1,060,728$ take place in the peak season; tourists that come in the off-season have only 212,353 nights.

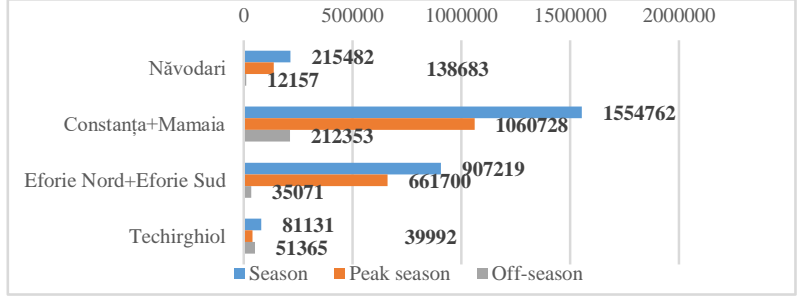

Figure 11 Seasonality of Tourist Demand in the Northern Core-Periphery Area (Tourist Overnight). Source: N.S.I.

Eforie Nord and Eforie Sud have just over 900,000 overnight stays, of which 661,600 are in season, to which are added 35,071 overnight stays.

Techirghiol has a special configuration, the number of arrivals in the off-season is almost two thirds higher than that of arrivals in the peak season (51,365 to 39,992 overnight stays), with a total of 81,131 overnight stays.

The following is noted in the analysis of the seasonality in the Southern Area of the seaside:

- Costinesti resort is exclusively seasonal, with 208,096 overnight stays being registered, of which 188,794 overnight stays are between July and August;

- similar situations, with a very small number of overnight stays in the off-season (for example, 442 overnight stays in Limanu Commune), are found in Mangalia, localities in the Comorova Forest Area (with the resorts Saturn, Venus, Cap Aurora, Jupiter and Neptun-Olimp), and the localities of 2 Mai and Vama Veche. And yet, the pressure during the peak period is less visible than in the case of Costinesti Resort, even if in Limanu Commune tourists generate 43,720 overnight stays out of a total of 54,315 overnight stays.

- those arriving in off-season in Mangalia and the seaside towns adjacent to the Comorova Forest come for spa treatments.

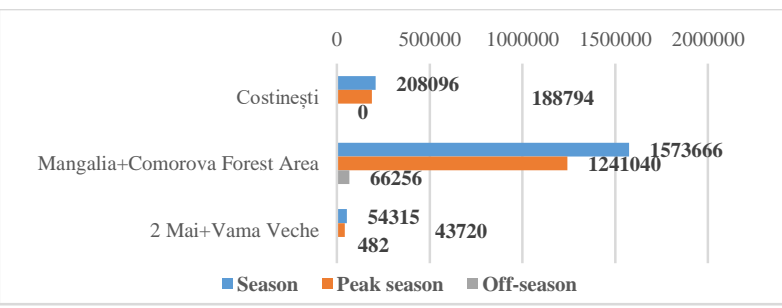

Figure 12 Seasonality of Tourist Demand In The Southern Core-Periphery Area (Tourist Overnight). Source: N.S.I. 


\section{c) Length of Stay}

The length of stay in the resorts on the southern Black Sea seaside is generally positive, increasing between $11.80 \%$ and $56.20 \%$.

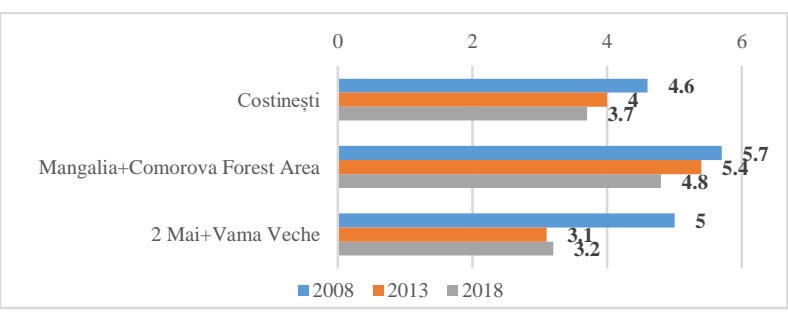

Figure 13 Length of Stay (Number of Days) in the Southern Core-Periphery Area Between 2008-2018. Source: N.S.I

The 2 Mai-Vama Veche area had the highest increase, of $56.20 \%$, the duration of the stay increasing from 3.2 tourist-days (2008) to 5 touristdays (2018). The lowest increase is found in the Mangalia - Comorova Forest Area, with only $11.80 \%$ (from 4.8 in 2008 to 5.7 tourist-days in 2018). Costinesti also had a constant increase, with $24.30 \%$, starting from 3.7 tourist-days in 2008 to 4.6 touristdays in 2018.

It is observed that compared to the Northern Core-Periphery Area (except Techirghiol), the number of overnight stays is about 2-3\% higher: the reason is that young people prefer to come on weekends to cheap resorts which offer enough entertainment, and others prefer quiet family resorts in Mangalia and Comorova Forest.

\subsection{Comparison between the Northern and the Southern Area}

Seasonality is a basic feature of tourism activity, regardless of country or continent and there will always be a negative impact on the destination when there is a massive concentration of tourism demand. This impact will lead to effects such as the degree of satisfaction of tourists, on the labor force in the industry, on the environment, etc.

From the point of view of the Romanian tourism industry, the most affected region is the South-East, more precisely for the part in the immediate vicinity of the seaside.

\section{a) Tourist Arrivals}

The most visited destination on the seaside remains Constanta together with Mamaia Resort in the
North Center in a percentage of $47.70 \%$, followed by Mangalia and the Comorova Forest in the South with an average of $27.30 \%$, the difference between them being a little over $74 \%$.

In third place are Eforie Nord and Eforie Sud (North Area) with an average of $15 \%$, followed by several areas below 5\%: in the North Area, Navodari - 3.50\%, Techirghiol $-1.20 \%$, and in the South Area Costinesti - 3.10\%, Limanu (2 Mai and Vama Veche) $-0.93 \%$.

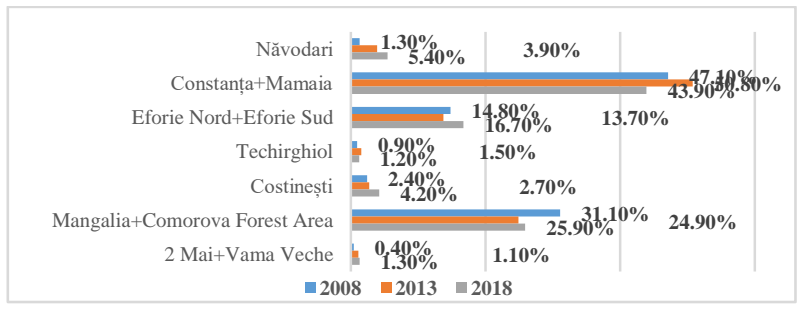

Figure 14 Tourist Arrivals (\%) in the Northern Vs. the Southern Core-Periphery Area Between 2008-2018. Source: N.S.I

The analysis of this dynamic highlights the fact that tourists prefer the Northern Area, more precisely the most strongly developed on the seaside, Mamaia. This can be seen in the relatively large increases in Navodari, Limanu or Techirghiol, but the distribution is based on several conditions that will be analyzed later.

In absolute numbers, the largest increases were noted in the Municipality of Constanta, where, in 2018, 114,612 more tourists stayed than in 2008 and 139,152 more tourists compared to 2013.

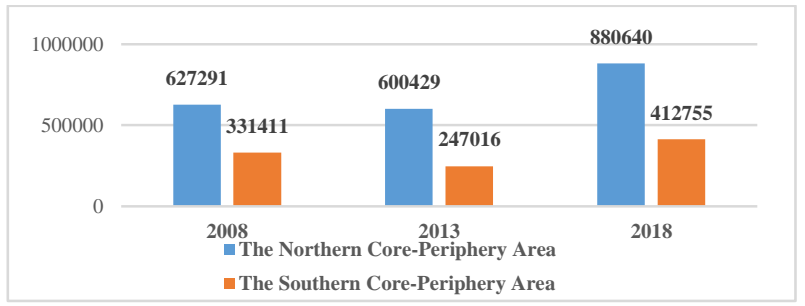

Figure 15 Tourist Arrivals in the Northern Vs. The Southern Core-Periphery Area Between 2008-2018. Source: N.S.I.

Using the data of the National Institute of Statistics for 2018, it can be seen that in 2018 the Romanian seaside received the most tourists from the entire county of Constanta. 


\section{b) Overnight stays}

The structure between the North and the South Area is preserved here as well. Thus, Constanta and Mamaia are around the average value of $38.20 \%$, followed by Mangalia and the Comorova Forest Area with $35.20 \%$. Tourists, at the level of 2018, reduced the number of overnight stays in the mentioned localities by approximately $7.30 \%$ in the North and by almost $19.90 \%$ in the South; thus we can notice, once again, the fact that tourists prefer the North more than the South.

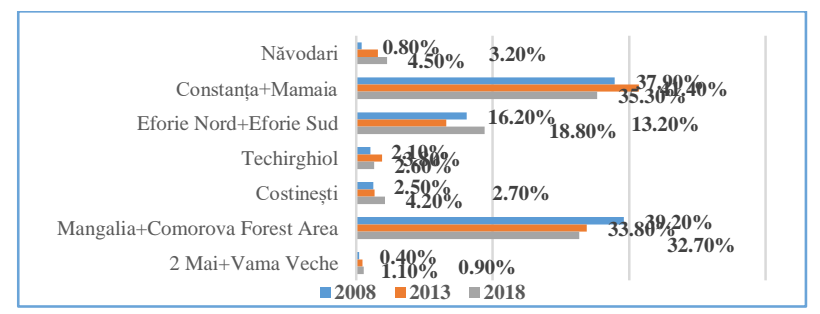

Figure 16 Tourist Overnight Stays (\%) in the Northern Vs. the Southern Core-Periphery Area Between 20082018. Source: N.S.I.

A special structure is the annual distribution of the peaks of overnight stays:

- in 2008, Mangalia and the localities in the Comorova Forest Area reached a maximum of $39.20 \%$, showing that tourists preferred either to go with family or friends.

- in 2013, 5 years after the world economic crisis, most tourists went to the Constanta-Mamaia group, wanting to have fun by the highest standards. Techirghiol, too, is gaining about $81 \%$ compared to 2008 , taking tourists from the group of the two Eforie.

- in 2018, the influence of strong resorts decreases in favor of smaller resorts (Navodari, Eforie Nord and Eforie Sud in the North Area, respectively Costinesti and Limanu commune - 2 Mai and Vama Veche in the South area), a trend of stability in their choice being noticed.

And yet, in the battle of North versus South, the North wins, with a surplus of 2,654,396 nights spent by tourists on the seaside, which shows that the North will continue to have a demand from them in the coming years.

The number of overnight stays made by tourists in Constanta County shows that the largest agglomerations take place on the coastline dedicated for this purpose, occupying more than half of the $80 \mathrm{~km}$ located on Romanian territory. The farther we go from the shore, the number of tourists decreases to insignificant values, which are not taken into account in the present research.

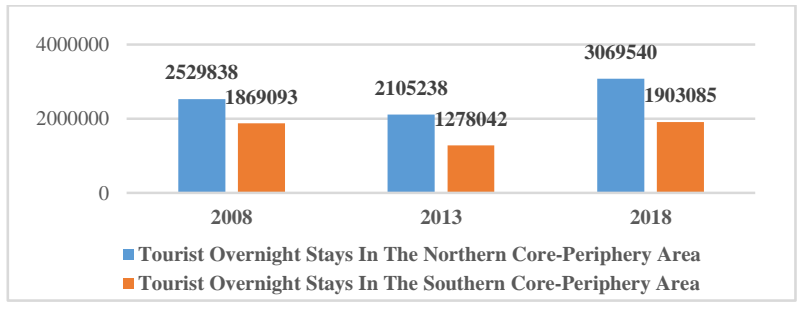

Figure 17 Tourist Overnight Stays in the Northern Vs. the Southern Core-Periphery Area. Source: N.S.I.

\section{c) Length of stay}

Spending the stay is a challenge for any commercial enterprise in the industry, which tries, by (almost) any means to keep the tourists close. However, according to reports, at the North-South level, the same trend of spending the stay in the North Area to the detriment of the South is occurring.

The decrease of tourist days during the stay in the Northern Area is approximately $17.40 \%$ (from 5.6 in 2018 to 4.77 tourist days in 2018), with the Southern Area losing more than $30.70 \%$ of their total in the same period (from 5.1 to 3.9 tourist days).

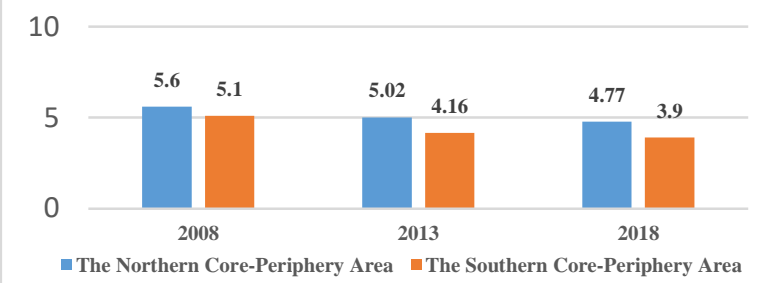

Figure 18 Length of Stay (Number of Days) in the

Northern Core-Periphery Area Vs. the Southern

Core-Periphery Area Between 2008-2018. Source: N.S.I.

\section{d) Seasonality}

\section{1) Tourist arrivals}

The seasonality of the tourist demand between the North and South Core-Periphery Area is shown in the graph below:

\section{- The North Core-Periphery Area:}

a) Navodari Resort: out of the total number of tourists arriving here, $11.90 \%$ come in the offseason, and $49.10 \%$ of them come in the peak season; 
b) in Constanta and Mamaia: $17.20 \%$ come in the off-season, $52.50 \%$ in the peak season and only $29.80 \%$ come in the rest of the time;

c) Eforie Nord and Eforie Sud: most tourists arrive during the peak period $(67.70 \%)$, with few of them coming in the off-season $(5.60 \%)$;

d) Techirgiol: breaks the record for arrivals in the off-season $(31.50 \%)$, almost at the same value as those coming in the peak season: $33.60 \%$.

- The South Core-Periphery Area:

a) Costinesti: has the highest number of arrivals in the peak season on the Romanian seaside $(89.20 \%)$, not being appreciated in the off-season $(0.00 \%)$;

b) Mangalia and the localities from the Comorova Forest Area: in the off-season very few come, only $2.70 \%$, the peak of the season being the most appreciated in this resort (76.20\%).

c) Limanu Commune (2 Mai and Vama Veche localities): arrivals in the off-season are insignificant (only $0.80 \%$ ), the arrivals from the peak season being $73.20 \%$ ).

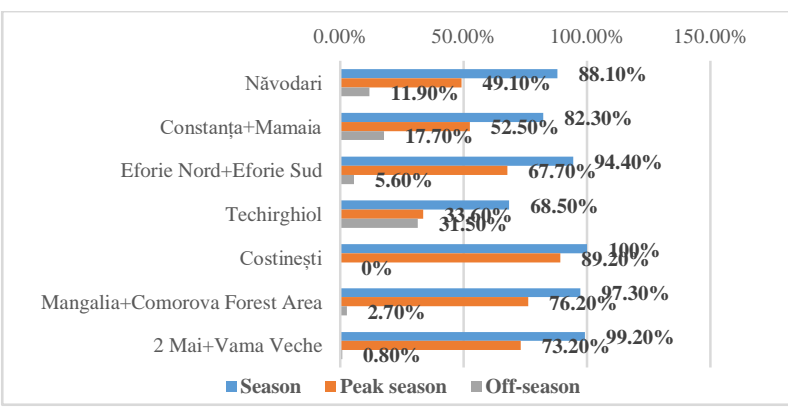

Figure 19 Seasonality of Tourist Demand in the Northern Versus the Southern Core-Periphery Area. Source: N.S.I.

Looking at these data, we conclude that tourists appreciate the North more than the South during the summer season, but the ratio is reversed, with more tourists coming to the South during the off-season.

The exceptions are the following: in Techirghiol, in the off-season, we have the highest number of arrivals, and in Costinesti no arrivals. The reason is, as we have shown, that Techirgiol has treatment complexes that work all year round.

The distributions of arrivals are very clear comparing the two Areas: most prefer the summer season, of which more than half come in the peak season. Arrivals in the off-season are only $38.50 \%$ higher in the North than in the South.

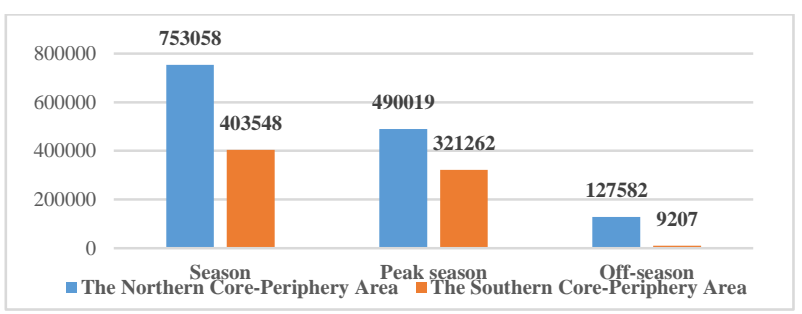

Figure 20 Seasonality of Tourist Arrivals in the Northern Versus the Southern Core-Periphery Area (Tourist Arrivals). Source: N.S.I.

\section{2) Overnight stays}

The conclusions drawn from the overnight stays in terms of seasonality show that most tourists prefer to come at the peak of the season (from $60.00 \%$ in Constanta and Mamaia to $90.70 \%$ in Costinesti), with relatively few tourists in the off-season $(12.00 \%$ in Constanta and Mamaia) or not at all $(0.00 \%$ in Costinesti).

The exception to this rule is Techirghiol, which, having open treatment spas (treatment that requires time to alleviate diseases), works all year round. Let us not forget that, in winter, the prices in the accommodation offers are much lower than in season or in the peak one, thus more and more tourists come here out of season.

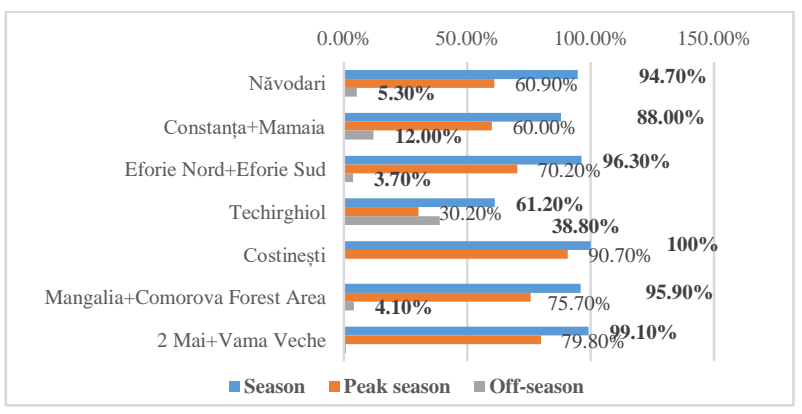

Figure 21 Seasonality of Tourist Demand in the North Versus the Southern Core-Periphery Area (Tourist Overnight). Source: N.S.I.

The differences obtained as a result of the processing show that the Northern Area is also more prolific in terms of overnight stays, the differences between the two being $33.40 \%$ during the summer season, $22.50 \%$ in the peak season and $78.50 \%$. in the off-season.

We can also see here that in the peak season most tourists spend the night on the Romanian seaside, due to the high and long-lasting temperatures during the summer and employers grant the period of compulsory leave in July-August. 


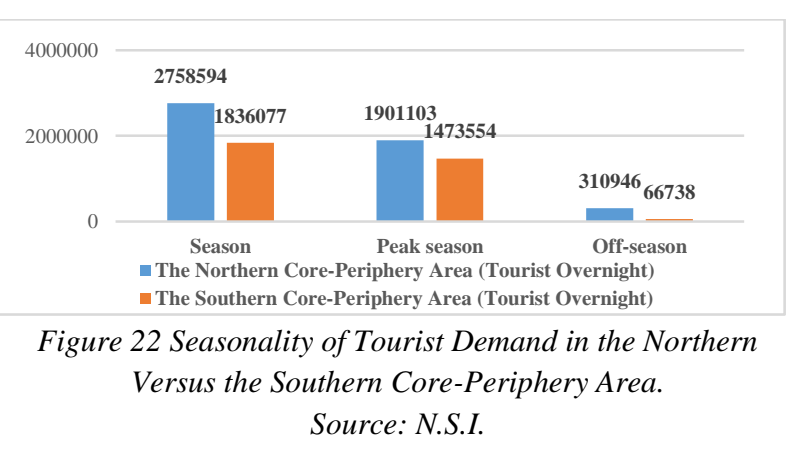

\section{e) Tourism Demand-Supply Ratio}

The index that links supply and demand is called the occupancy rate (index of net use of accommodation). It highlights the degree to which accommodation capacities are capitalized in terms of overnight stays.

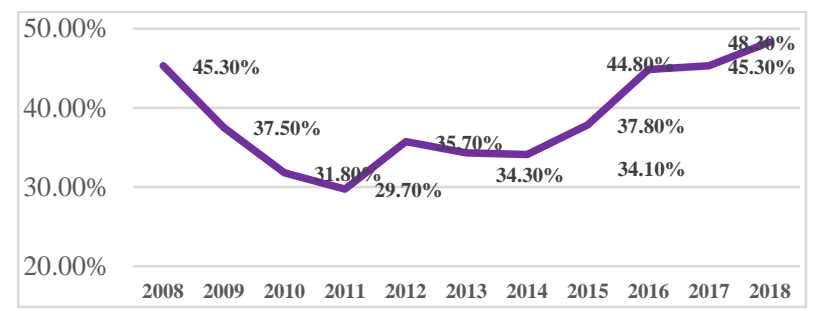

Figure 23 Index of Net Use of Accommodation Places on

The Seaside (2008-2018)Source: N.S.I.

In terms of developments in the last decade (2008-2018), three distinct periods are identified:

- period 2008-2011: against the background of the economic crisis, all indices decrease, the occupancy rate decreasing by $15.60 \mathrm{pp}$, from $45.30 \%$ to $29.70 \%$;

- 2012-2014: the index is recovering, but not strong enough to hold. Thus, although in 2013 it reaches $35.70 \%$, it then decreases by $1.20 \mathrm{pp}$ (percentage points);

- 2014-2018: following the return of world economic exchanges, there is a steady increase in the index of net use of accommodation, from $34.10 \%$ to $48.30 \%$.

Following the curve for the decade 2008-2018, we can see that only after 9 years the occupancy rate reached the same level in the first year $(45.30 \%)$. Another observation found is that the annual average occupancy is usually below $50 \%$ of the total operating accommodation capacity.

Perhaps it is useful to show the evolution of the occupancy rate of accommodation structures during
2018. As expected, based on previous analyses, there are very large differences between the maximum peak of the season (July-August) and the other months of year, given that in the off-season many units close.

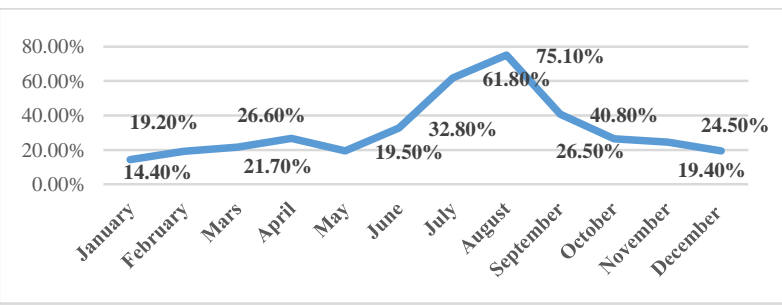

Figure 24 Index of Net Use of Accommodation Places on The Seaside (Every Month, 2018)Source: N.S.I.

Therefore, a large share of accommodation structures operate at a loss (almost $25 \%$ of them do not have enough tourists in the peak season), and in these conditions many of them close in the offseason to reduce losses.

In order to increase the value of the index of net use of accommodation structures, it is necessary, among others, to extend the summer season, both at hotel and destination level.

\section{CONCLUSIONS}

Following the analysis carried out throughout this article, we can observe that the Northern CorePeriphery Area is stronger than the South one in all respects. The fact that more and more customers are investing in this area also attracts the most customers.

A 2015 report of the National Bureau of Economic Research from the United States (https://www.nber.org) shows that, from any position we look (geographical, economic, etc.), the northern part will be more developed than the south, being influenced by four factors: it has access to the sea, natural resources, good conditions for agriculture, and the climate is cold or warm.

In the case of our country, and especially on the Black Sea seaside, the northern part meets all four requirements, while the south meets only three, lacking agriculture.

From the Danube Delta to Eforie Nord there is a flat, rich plateau, beneficial to the economy, while the south, as a remnant of prehistoric mountains, 
has high, stony cliffs, being ruinous in terms of certain branches.

This hypothesis of American researchers is much richer in examples; however, if we adapt it to our country, we can notice that the choice of localities within the North-South Core-Periphery Areas is not purely coincidental, the differences being visible in the analyses.

From the point of view of the influences of the administrative-territorial units, as they are structured, the choice of these areas is the correct one and, in addition, all studies tend to take these details into account.

In conclusion, the North Area is, on average, 50\% stronger in all domains (especially economical) than the South one, having the greatest influence in the analyses carried out so far.

\section{REFERENCES}

Fujita, M., Krugman, P, Venables A.J. (2001). The Spatial Economy. The MIT Press, USA.

Goeldner, Charles, J. and Ritchie, J.R. (2011). Tourism: Principles, practices, philosophies, Publishing House: John Wiley and Sons Inc., USA.

Krugman, P. (1991). Increasing returns and economic geography Journal of Political Economy, 99, 483-499.

Lickorish, L. and Jenkins, C. (2000). Introdução ao turismo. Campus. Rio de Janeiro. Brasil.

National Bureau of Economic Research, USA https://www.nber.org. 